\title{
Crosstalk between the AMP-activated kinase and insulin signaling pathways rescues murine blastocyst cells from insulin resistance
}

\author{
Erica Louden, Maggie M Chi and Kelle H Moley \\ Department of OB/GYN, Washington University School of Medicine, 7th Floor McDonnell Science, 660 S. Euclid \\ Avenue, Campus Box 8064, St Louis, Missouri 63110, USA \\ Correspondence should be addressed to K H Moley; Email: moleyk@wustl.edu
}

\begin{abstract}
Maternal insulin resistance results in poor pregnancy outcomes. In vivo and in vitro exposure of the murine blastocyst to high insulin or IGF1 results in the down-regulation of the IGF1 receptor (IGF1R). This in turn leads to decreased glucose uptake, increased apoptosis, as well as pregnancy resorption and growth restriction. Recent studies have shown that blastocyst activation of AMP-activated protein kinase (AMPK) reverses these detrimental effects; however, the mechanism was not clear. The objective of this study was to determine how AMPK activation rescues the insulin-resistant blastocyst. Using trophoblast stem (TS) cells derived from the blastocyst, insulin resistance was recreated by transfecting with siRNA to Igf1 $r$ and down-regulating expression of the protein. These cells were then exposed to AMPK activators 5-aminoimidazole-4-carboxamide riboside and phenformin, and evaluated for apoptosis, insulin-stimulated 2-deoxyglucose uptake, PI3-kinase activity, and levels of phospho-AKT, phospho-mTor, and phospho-70S6K. Surprisingly, disrupted insulin signaling led to decreased AMPK activity in TS cells. Activators reversed these effects by increasing the AMP/ATP ratio. Moreover, this treatment increased insulin-stimulated 2-deoxyglucose transport and cell survival, and led to an increase in PI3-kinase activity, as well as increased P-mTOR and p70S6K levels. This study is the first to demonstrate significant crosstalk between the AMPK and insulin signaling pathways in embryonic cells, specifically the enhanced response of PI3K/AKT/mTOR to AMPK activation. Decreased insulin signaling also resulted in decreased AMPK activation. These findings provide mechanistic targets in the AMPK signaling pathway that may be essential for improved pregnancy success in insulin-resistant states.
\end{abstract}

Reproduction (2008) 136 335-344

\section{Introduction}

Approximately $5-7 \%$ of reproductive-age women have polycystic ovary syndrome (PCOS), characterized by hyperandrogenism, oligomenorrhea, and multiple ovarian cysts (Gilbert et al. 2006). Although a common cause of infertility, these women can conceive with ovulation induction; however, they experience a much higher incidence of pregnancy complications such as gestational diabetes, insulin resistance, hypertension, as well as spontaneous miscarriages and the birth of small for gestational age or large for gestational age babies. In addition, maternal hyperinsulinemia due to other maternal conditions such as type 2 diabetes and obesity is implicated in impaired embryo implantation, congenital malformations, and early pregnancy loss (Homburg 2006). Elevated levels of insulin-like growth factor-1 (IGF1) or insulin are characteristic of hyperinsulinemic obese or PCOS patients and negatively affect development of the blastocyst and the preimplantation embryo, suggesting that these hormones and growth factors may be responsible for the increase in poor pregnancy outcome in women with these metabolic disorders (Thierry van Dessel et al. 1999, Chi et al. 2000). Understanding the pathways that regulate glucose uptake and insulin sensitivity in the embryo is critical to improving pregnancy outcomes associated with maternal hyperinsulinemia.

The mammalian preimplantation embryo is a unique stage in embryonic development (Zernicka-Goetz 2002, McGraw et al. 2003). It is at this time that the cells of the embryo segregate into two morphologically and functionally distinct cell lineages. One is the inner cell mass, and the other is the trophectoderm (Riley et al. 2005, Tanaka 2006). Trophoblast stem cells (TS) are derived from trophectoderm. The trophectoderm and later the trophoblast cells mediate implantation and ultimately become the placenta (Nichols et al. 1998). Both the insulin and IGF1 receptors (IGF1R) are expressed in the trophectoderm cells and trophoblast tissue, suggesting that their ligands, insulin and IGF1, are regulators of embryonic growth (Diaz et al. 2005). High 
concentrations of insulin or IGF1 lead to internalization of their receptors, affecting downstream signaling pathways. This desensitization triggers an apoptotic cascade as seen with several other cell types. Downregulation or blockade of insulin or IGF1R also leads to the same outcome (Chi et al. 2000, Hiromura et al. 2002, Kim et al. 2005, Morgensztern \& McLeod 2005, Riley et al. 2005, 2006). In addition, it has been shown that insulin receptor down-regulation by anti-sense oligonucleotides can lead to increased apoptosis in the neurulating chicken embryo and preimplantation blastocyst (Morales et al. 1997, Chi et al. 2000). Furthermore, insulin and IGF1 stimulate glucose uptake in the preimplantation blastocyst via the IGF1R (Chi et al. 2000). Insulin-stimulated glucose uptake has also been shown to be regulated by glucose transporter 8 (GLUT8, now known as solute carrier family 2, member 8 , SLC2A8) translocation to the plasma membrane in the blastocyst (Carayannopoulos et al. 2000).

AMP-activated protein kinase (AMPK) is a fuel-sensing heterotrimeric kinase, which acts as a key regulator in glucose and fatty acid metabolism (Hardie et al. 2003, Kahn et al. 2005) and which is activated in response to a rise in AMP/ATP (Guigas et al. 2006). The main phosphorylation site responsible for the activation of AMPK is Thr172 within the catalytic domain of the $\alpha$-subunit. Although, AMPK $\gamma 2$ is abundantly expressed in human placenta (Lang et al. 2000) and AMPK $\alpha 1$ is the predominant isoform in the mouse oocyte (Downs et al. 2002), little is known about AMPK activation and metabolic effects on glucose uptake in the preimplantation embryo. Studies have shown that AMPK is likely to be a major factor in modulating the response of the endothelium to stresses that alter its energy state in human umbilical vein endothelial cells (HUVEC) (Dagher et al. 1999). In addition, studies by Ido et al. (2002) suggested that AMPK could play an important role in protecting the endothelial cell of HUVECs against the adverse effects of sustained hyperglycemia, in which there is increased apoptosis and impaired AKT phosphorylation. TS cells provide an ideal system for examining signaling in trophoblast proliferation, implantation, and have been widely used and characterized by the Rossant laboratory (Tanaka et al. 1998, Ralston \& Rossant 2006, Rossant 2008). We have recently developed a unique model to investigate the effects of maternal hyperinsulinemia using TS cells derived from the murine preimplantation embryo. By down-regulating the expression of the IGF1R using siRNA in TS cells, we are mimicking the embryonic response to elevated IGF1 or insulin concentrations, and thus recreating the conditions of maternal hyperinsulinemia. We chose the knockdown of IGF1R as the model of insulin resistance because IGF1R and insulin receptors are $80 \%$ homologous and share several signaling pathways (Riedemann \& Macaulay 2006). Also, in the preimplantation blastocyst glucose uptake has been shown to operate via the IGF1R only (Chi et al. 2000). Furthermore, overexpression of a dominant-negative IGF1R in skeletal muscle in mice is a proved model of severe insulin resistance and type 2 diabetes (Yakar et al. 2005). We have recently shown that dysregulation of AMPK activity as a result of insulin resistance in the blastocyst increases apoptosis, decreases 2-deoxyglucose transport, and leads to poor pregnancy outcomes in the mouse model (Eng et al. 2007). We hypothesize that that crosstalk exists between the AMPK and insulin signaling pathways during early embryonic development and that heightened response of the insulin signaling pathway downstream from the IGF1R to AMPK activation rescues these cells. We anticipate that this study may elucidate alternative signal transduction pathways crucial for pregnancy success in insulin-resistant state.

\section{Results \\ Igf1r siRNA treatment decreases AMPK activity and is reversible by AMPK activators}

Excess IGF1 or insulin leads to the down-regulation of IGF1R and an insulin-resistant blastocyst (Chi et al. 2000, Pinto et al. 2002 b, Adamiak et al. 2005); however, little is known about how the dysfunction of this signaling pathway impacts on embryonic cell signaling. We sought to characterize this pathway by recreating insulin resistance in TS cells by transfection with Igf1r siRNA. In the presence of $10 \mathrm{nM}$ Igf1r siRNA for $72 \mathrm{~h}$, IGF1R $\beta$ total protein levels were reduced by $60 \%$ and plasma membrane IGF1R $\beta$ by $45 \%$; shown by western immunoblotting and flow cytometry (Fig. $1 \mathrm{~A}$ and B). The decrease at $72 \mathrm{~h}$ in receptor expression is similar to what has been reported previously with high IGF1 concentrations in the blastocyst (Chi et al. 2000, Pinto et al. $2002 b)$. The efficiency of Igf1r siRNA was comparable with high IGF1 (130 nM) and insulin $(1 \mu \mathrm{M})$ knockdown of IGF1R (Fig. 1C). Since AMPK is a modulator of glucose uptake in the blastocyst (Eng et al. 2007), we hypothesized that dysregulation of AMPK may be involved in the TS cell response to decreased IGF1R signaling. To test our hypothesis, we examined phosphorylated AMPK (pAMPK) and total AMPK protein by western immunoblot analysis of total cell lysate from the TS cells with IGF1R knockdown. As shown in Fig. 2A, IGF1R knockdown resulted in decreased pAMPK, whereas treatment with $250 \mu \mathrm{M}$ of 5 -aminoimidazole4-carboxamide riboside (AICAR) or $10 \mathrm{mM}$ phenformin for $2 \mathrm{~h}$ normalized AMPK activity. In addition, inhibition of AMPK activity by compound C $(125 \mu \mathrm{M})$ decreases AICAR effects on AMPK and reversed the increase in PAMPK, suggesting that the results were due to AMPK activity. The resulting doublet in the compound C-treated cells may be the result of a protease sensitive site within pAMPK $\gamma$-subunit (Barnes et al. 2004). Finally, to verify that down-regulated IGF1R was 


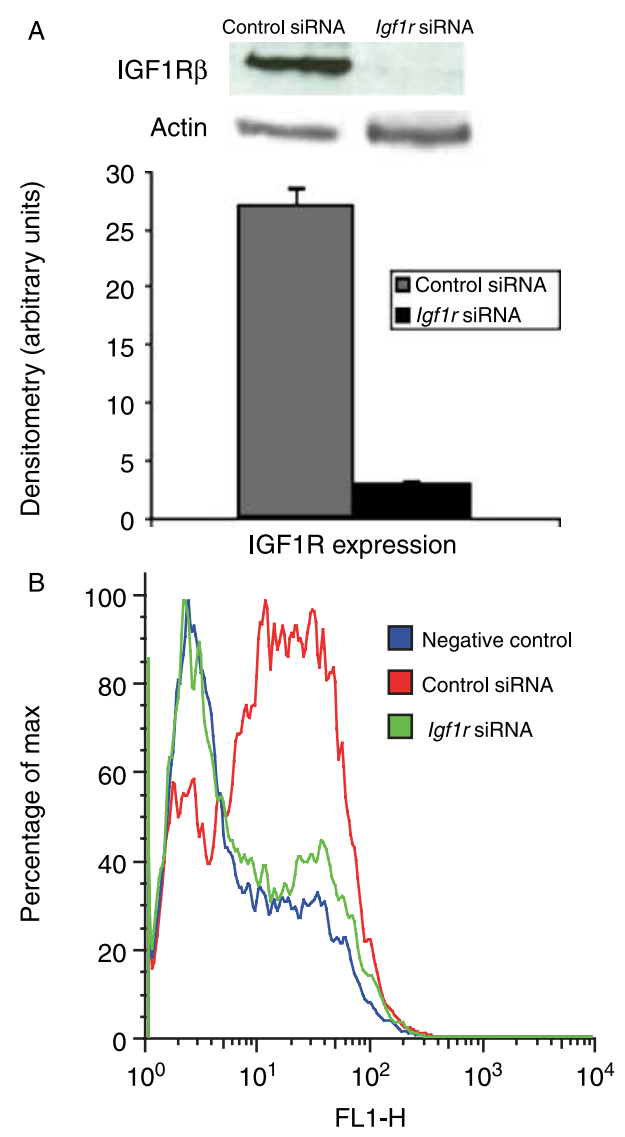

FACS: IGF1R $\beta$ PM expression

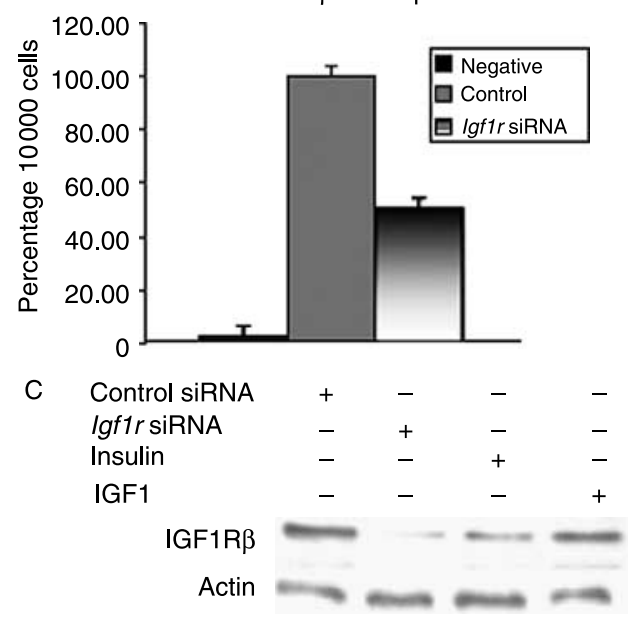

Figure 1 Igf1 $r$ siRNA knockdown of IGF1R $\beta$ expression. (A) TS cells transfected with $10 \mathrm{nM}$ Igf1r siRNA and harvested after $72 \mathrm{~h}$ demonstrated decreased protein expression. Whole cell lysates were analyzed by immunoprecipitation and western immunoblotting with antibodies to IGF1R $\beta$ and $\beta$-actin. The western blot was quantitated using densitometry and $\mathrm{NIH}$ Image software, and was normalized to $\beta$-actin in the corresponding graph. (B) Cell surface expression of IGF1R $\beta$ was also decreased in the Igf1 $r$ siRNA-treated cells. This difference was assessed and quantitated by flow cytometry. (C) Exposure to high concentrations of insulin or IGF1 resulted in a similar decrease in IGF1R $\beta$ protein as shown previously in blastocysts. This experiment was similar to that in A. affecting the AMPK signaling pathway, we examined phosphorylated acetyl-CoA carboxylase (p-ACC), an enzyme involved in fatty acid synthesis and inhibited by AMPK through phosphorylation. P-ACC protein is decreased in the TS cells transfected with Igf1 $r$ siRNA in western immunoblot analysis and is also increased with AICAR or phenformin treatment; however, total ACC protein is not affected by these treatments (Fig. 2B).

To elucidate how down-regulation of IGF1R affects AMPK activation in TS cells, experiments were performed to measure AMP/ATP ratios. AMP/ATP was measured in the TS cells transfected with Igf1r siRNA and cultured in control medium or in the medium containing $250 \mu \mathrm{M}$ AICAR or $10 \mathrm{mM}$ phenformin for $2 \mathrm{~h}$. TS cells with decreased IGF1R protein show a $36 \%$ decrease in AMP/ATP when compared with the control (Fig. 3). Treatment with AICAR, however, reversed this effect and indirectly restored AMP/ATP to control levels, a significant $57 \%$ increase (Fig. 3). AICAR acts as an AMP mimetic via ZMP analogs. However, studies have shown that AICAR is an inhibitor of AMP deaminase that inhibits the conversion of AMP to IMP and may be responsible for the increase in AMP in our studies (Gruber et al. 1989, Culmsee et al. 2001, Chan et al. 2007). Furthermore, addition of phenformin greatly increased AMP/ATP threefold (309\%). As reported previously, phenformin is a biguanide that inhibits complex I of the mitochondrial respiratory chain and dramatically drops ATP and increases AMP levels as seen here (Woollhead et al. 2005; Fig. 3).

\section{AMPK activators reverse Igf1r siRNA-induced decreases in 2-deoxyglucose uptake and SLC2A8 cell surface expression}

Insulin-regulated embryonic transporter SLC2A8 (GLUT8) is necessary for murine blastocyst survival (Pinto et al. 2002a). We have previously shown that a decrease in glucose transport results in apoptosis at the blastocyst stage (Pinto et al. 2002a). Because AMPK activation has been linked with glucose uptake (Ye et al. 2006), we investigated whether activation of AMPK with the AMPK activator AICAR results in a change in 2-deoxyglucose uptake in TS cells transfected with Igf1r siRNA. Radioactive $\left[{ }^{3} \mathrm{H}\right] 2$ deoxyglucose uptake in insulin-resistant TS cells in the presence of $1 \mu \mathrm{M}$ insulin resulted in a $48 \%$ decrease in 2-deoxyglucose uptake when compared with control TS cells. Alternatively, stimulation with $250 \mu \mathrm{m}$ AICAR resulted in $157 \%$ increase in 2-deoxyglucose uptake (Fig. 4A). Furthermore, in Fig. 4B, we show an increase in insulin-stimulated SLC2A8 translocation to the plasma membrane by cell surface photolabeling with $\mathrm{N}$-[2-[2-[2-[N-biotinyl-caproylamino)-ethoxy)ethoxyl]4-[2-(trifluoromethyl)-3H-diazirin-3yl]benzoyl]-1,3-bis (mannopyranosyl-4-yloxy)-2-propylamine (Bio-ATBBMPA) in insulin-resistant TS cells treated with $250 \mu \mathrm{M}$ AICAR for $2 \mathrm{~h}$. This study suggests that 
A

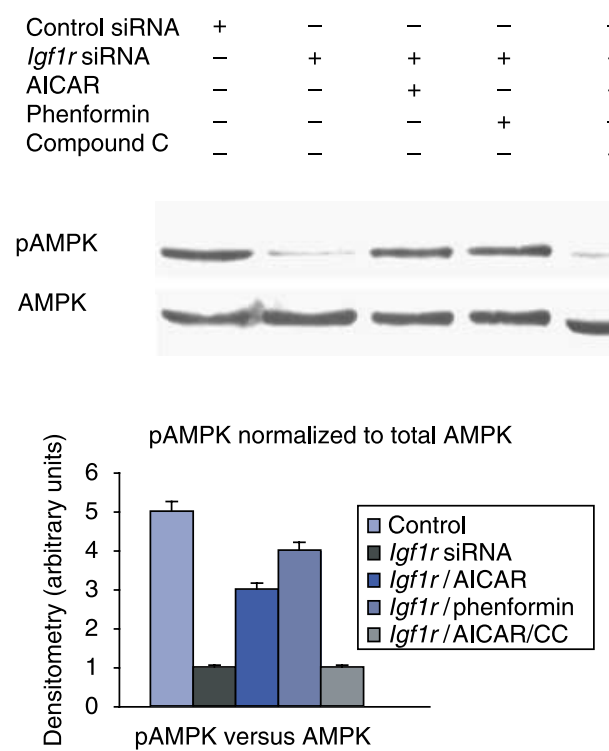

B
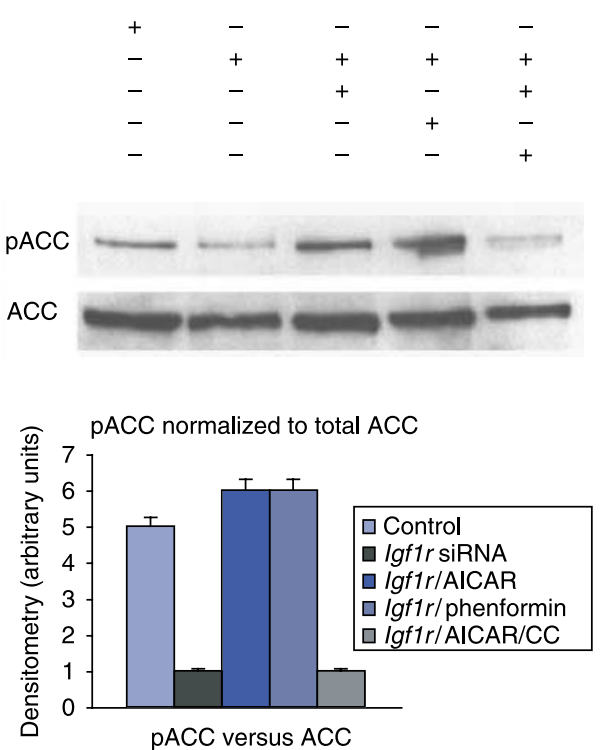

Figure 2 Igf1 r siRNA decreases PAMPK and p-ACC and AICAR and phenformin reverse this effect. Knockdown of IGF1R $\beta$ results in decreased AMPK activity as measured by (A) pAMPK over total AMPK protein and (B) ACC phosphorylation over total ACC protein. AMPK activators, AICAR (250 $\mu$ M), and phenformin $(10 \mathrm{mM})$ reversed this decrease. Compound $\mathrm{C}(\mathrm{CC}, 125 \mu \mathrm{M})$, an AMPK inhibitor, prevented AICAR and phenformin effects on AMPK. In the corresponding graphs, pAMPK and p-ACC western blots were quantitated using densitometry and NIH image software and were normalized to $\beta$-actin.

down-regulation of IGF-IR leads to decreased 2-deoxyglucose uptake and that activation of the AMPK pathway leads to a change in glucose transporter expression at the plasma membrane as reflected by the increase in SLC2A8 translocation. As a result, 2-deoxyglucose uptake in TS cells with decreased expression of IGF1R is normalized by AMPK activation.

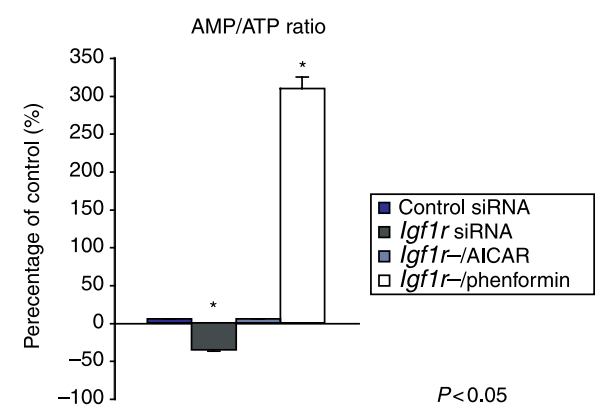

\begin{tabular}{|lccccc|}
\hline \multicolumn{1}{|c}{ TS cells } & $\begin{array}{c}\text { 5'AMP } \\
\text { (mM) }\end{array}$ & $\begin{array}{c}\text { ATP } \\
(\mathrm{mM})\end{array}$ & AMP/ATP & \multicolumn{2}{c|}{ Percent difference } \\
\hline Control siRNA & 0.423 & 3.73 & 0.11 & 0 & 57 \\
Igf1r siRNA & 0.271 & 3.519 & 0.07 & -36 & 0 \\
Igf1r-/AICAR & 0.631 & 5.71 & 0.11 & 0 & 57 \\
Igf1r-/phenformin & 0.792 & 1.77 & 0.45 & 309 & 543 \\
\hline
\end{tabular}

Figure 3 Igf1 $r$ siRNA decreases AMP/ATP in TS cells and AICAR and phenformin reverse this effect. Adenine nucleotide levels were analyzed as described in methods after $2 \mathrm{~h}$ incubation with AICAR $(250 \mu \mathrm{M})$ or phenformin $(10 \mathrm{mM})$. Concentrations are measured as $\mathrm{mM}$. The histogram depicts the difference as percentage of control siRNA. Values for the differences as percentage of Igf1 $r$ siRNA are given in the table. ${ }^{*} P<0.05$.

\section{AMPK activators reverse Igf1r siRNA-induced apoptosis}

Apoptosis was assessed by TUNEL assay after transfection with Igf1r siRNA for $72 \mathrm{~h}$ and treatment with $250 \mu \mathrm{M}$ AICAR for $2 \mathrm{~h}$. As shown by confocal immunofluorescent microscopy, TS cells underwent apoptosis as visualized by TUNEL positive nuclei with IGF1R knockdown. This effect was reversed by AICAR, whereas the addition of compound C $(125 \mu \mathrm{M})$ to the AICAR-treated cells eliminated the anti-apoptotic effects of AICAR in IGF1R knockdown TS cells and increased TUNEL positive staining (Fig. 5A). In addition, the TUNEL assay was analyzed by flow cytometry and this additional quantitative analysis confirmed a $36 \%$ decrease in apoptosis with AICAR treatment in the TS cells experiencing down-regulation of the IGF1R (Fig. 5B).

\section{AMPK activators reverse Igf1 $\mathrm{r}$ siRNA-induced decreases in PI3K/AKT and $m$ TOR activity}

In this experiment, decreased IGF1R expression led to decreased PI3K activity, and AMPK activation with AICAR reversed this effect (Fig. 6A) as measured by PI3K associated phosphotyrosyl activity. Likewise, decreased IGF1R knockdown in TS cells resulted in decreased serine 473 phosphorylation of AKT, required for full activation, whereas AICAR treatment increased levels of p-AKT shown by western immunoblot analysis (Fig. 6B). Other studies have shown that impaired signaling due to acute insulin resistance decreases AKT 

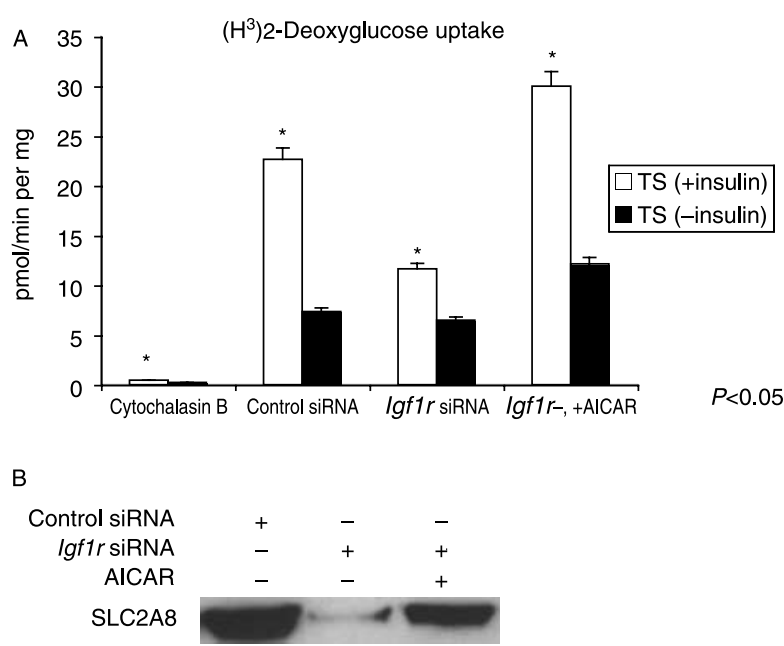

Figure 4 Down-regulation of IGF1R decreases insulin-stimulated 2-deoxyglucose uptake and SLC2A8 cell surface expression and is reversed by AICAR. (A) Uptake of $\left[{ }^{3} \mathrm{H}\right] 2$-deoxyglucose $(50 \mu \mathrm{M}, 30 \mathrm{~min}$ at RT) was measured 3 days after transfection with $10 \mathrm{nM}$ control siRNA or Igf1 $r$ siRNA and were incubated with AICAR $(250 \mu \mathrm{M})$ for $2 \mathrm{~h}$ in the presence or absence of insulin $1 \mu \mathrm{M}(30 \mathrm{~min})$. Insulin-stimulated 2-deoxyglucose uptake was significantly decreased in the IGF1R knockdown cells when compared with controls and increased with AICAR treatment. (B) The ATB-BMPA photolabel was used to tag SLC2A8 exposed at the cell surface of TS cells and the treated lysates immunoblotted using a SLC2A8 antibody. Cell surface SLC2A8 protein was then normalized to $\beta$-actin in the corresponding graph. ${ }^{*} P<0.05$.

phosphorylation and activation in rat skeletal muscle (Kim et al. 2006). The phosphorylation of mTOR by AKT activates mTOR to promote growth, proliferation, and survival by phosphorylation and activation of the translational machinery. Because AKT specifically phosphorylates mTOR Ser2448, we examined the effect of down-regulation of IGF1R on mTOR Ser2448 phosphorylation. In our study, IGF1R down-regulation resulted in decreased serine 2448 phosphorylation and activation of mTOR (Fig. 7A), as well as two of its putative downstream targets 70S6K Thr389 and S6Kribo Ser240/244 (Fig. 7B and C). As with AKT, these effects were reversed by the activation of AMPK with AICAR. The novelty of these findings is that activation of AMPK can reverse some of these downstream insulin signaling events, suggesting that crosstalk occurs between these two pathways.

\section{Discussion}

These findings suggest that insulin resistance in TS cells induced by down-regulation of IGF1R leads to abnormal AMPK activity as a result of a significant decrease in the ratio of AMP/ATP. We hypothesize that this dysfunction of AMPK may be responsible in part for the high incidence of poor quality embryos exposed to high insulin and IGF in mice and maybe women with insulin resistance. Insulin resistance in TS cells greatly decreases insulin-stimulated 2-deoxyglucose uptake, reduces cell surface SLC2A8 expression in response to insulin and increases apoptosis as seen in the blastocyst. Decreased AMPK activity is also evident; however, stimulation of AMPK activation with AICAR or phenformin reverses these detrimental effects. The present report is the first in an extra-embryonic cell system to demonstrate a relationship between IGF1R signaling and AMPK activity in response to the conditions induced by a maternal hyperinsulinemic environment. Rising levels of obesity and diabetes as well as the high prevalence of PCOS in reproductive-age women have led to increases in insulin resistance during conception and pregnancy. As a result, there has been a significant increase in risk for

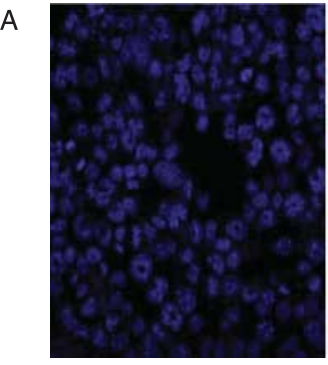

Control siRNA

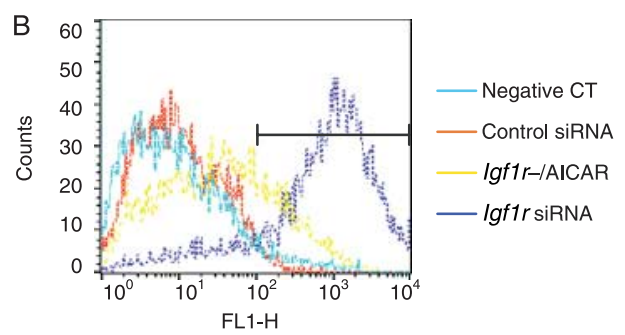

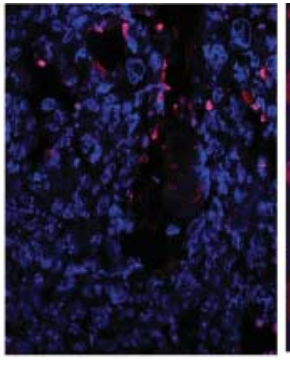

Igf1r-/AICAR

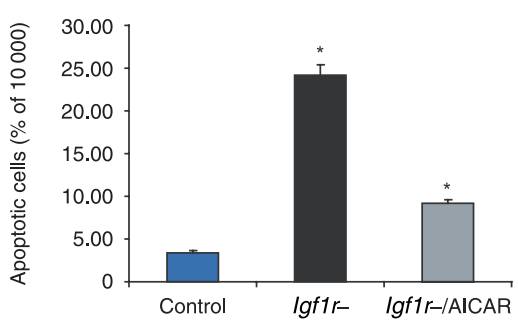

Figure 5 Knockdown of the IGF1R results in apoptosis that is reversed by AICAR in TS cells. (A) TS cells were transfected with $10 \mathrm{nM}$ control siRNA or Igf1r siRNA and were incubated with AICAR $(250 \mu \mathrm{M})$ and/or compound $C(125 \mu \mathrm{M})$ and examined for TUNEL-positive staining. The TUNEL assay was performed and the apoptotic nuclei are depicted in red. TS cells were counterstained with the nuclear dye TO-PRO-3 iodide shown in blue. (B) Percentage of TUNELpositive nuclei demonstrating DNA fragmentation as determined by flow cytometry with the corresponding graph. 


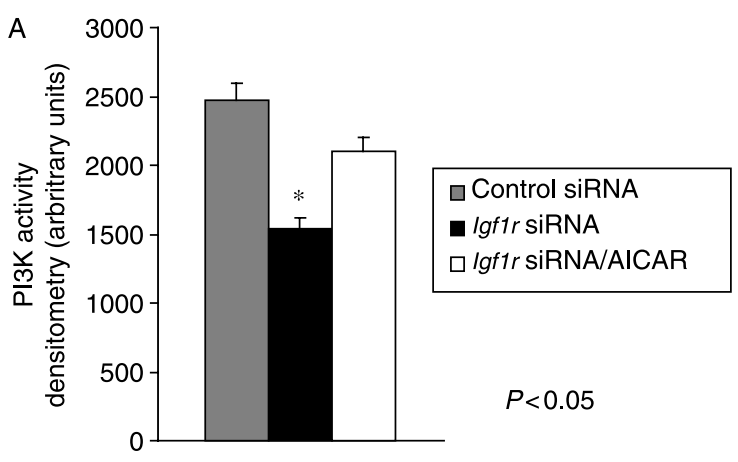

B

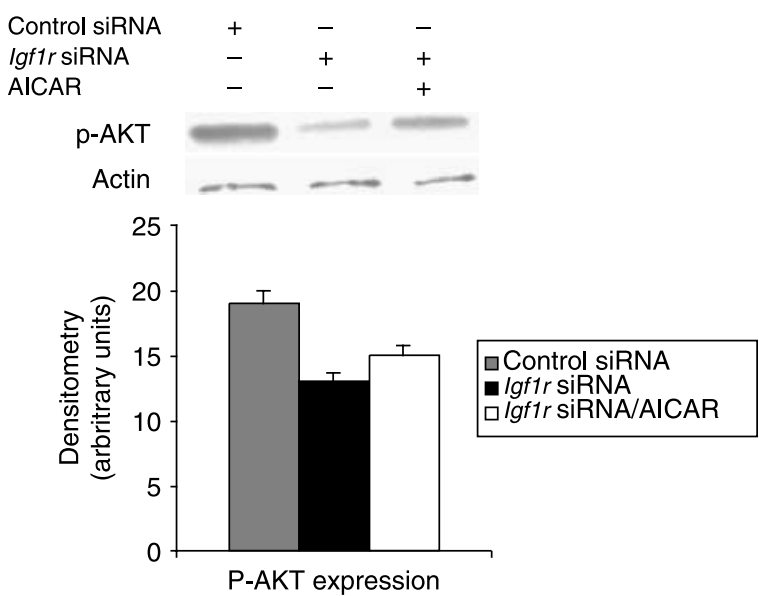

Figure $6 \mathrm{PI} 3 \mathrm{~K}$ and AKT activity are decreased by IGF1R downregulation and restored by AICAR stimulation of AMPK. (A) PI3-kinase activity as measured by ${ }^{32} \mathrm{P}$-labeled tyrosine phosphorylation was significantly decreased in TS cells transfected with $10 \mathrm{nM}$ Igf1 r siRNA versus control. (B) TS cells lysates were immunoblotted for active AKT (phospho-Ser473) 3 days after control or Igf1r siRNA transfection and incubation with AICAR $(250 \mu \mathrm{M})$ for $2 \mathrm{~h}$. In the corresponding graph, $\mathrm{p}$ AKT western blot was quantitated using densitometry and NIH Image software and was normalized to $\beta$-actin. ${ }^{*} P<0.05$.

reproductive abnormalities and one cause maybe due to dysregulation of the energy-sensing protein AMPK.

Other studies have suggested that AMPK activity regulates insulin sensitivity through positive control of insulin action (Ju et al. 2007). Our studies confirm and extend these reports of crosstalk between the pathways by demonstrating bidirectional activation. We propose that insulin resistance in our model exerts a negative effect on AMPK phosphorylation and activation, possibly by the decrease measured in AMP concentrations, leading to loss of allosteric activation of AMPK (Zang et al. 2004). Studies by Bakhle suggested that in streptozotocin-induced diabetes, less hydrolysis of ADP to AMP occurs in the lung and this could contribute to the decreased AMP levels detected (Bakhle \& Chelliah 1983). Furthermore, previous studies showed a uniform decrease in AMPK activity as measured by AMPK phosphorylation in liver, muscle, and fat of an insulinresistant model of Wistar rats (Satoh et al. 2004). Ratchford et al. (2007) also reported that maternal
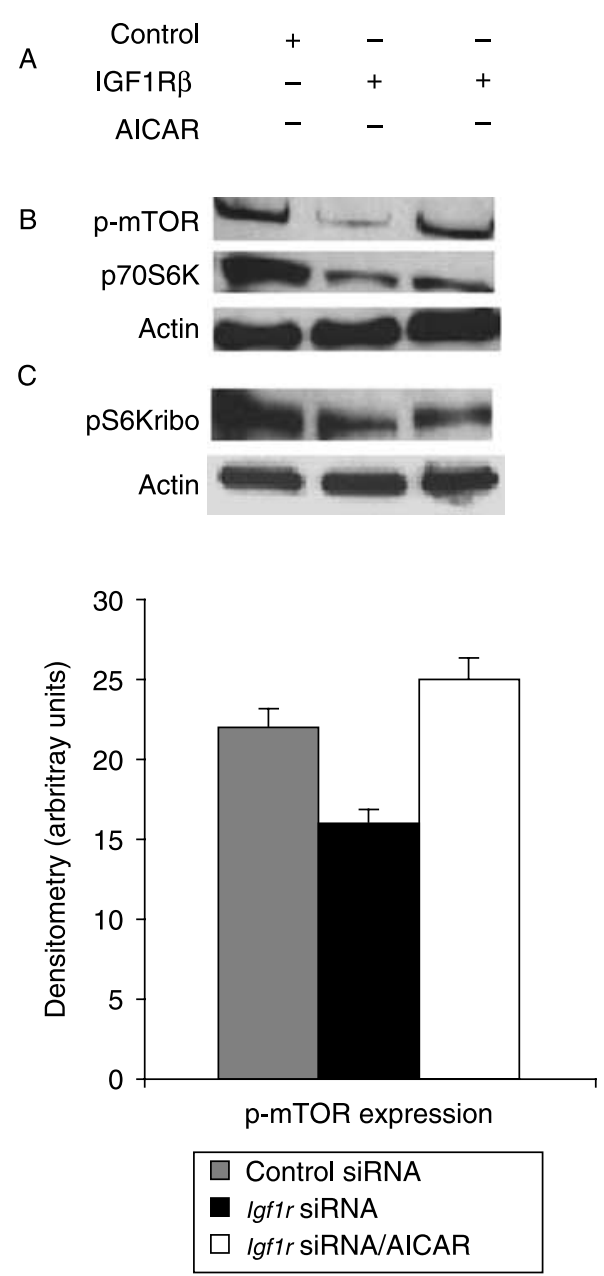

Figure 7 The effect of Igf1r siRNA on mTOR signaling pathway is reversed by AICAR. TS IGF1R knockdown cells were incubated $2 \mathrm{~h}$ with AICAR $(250 \mu \mathrm{M})$. Lysates were harvested and analyzed by western blotting using antibodies specific for (A) p-mTOR, (B) p70S6K, and (C) pS6Kribo. The p-mTOR western blot was quantitated using densitometry and NIH image software and normalized to $\beta$-actin in the corresponding graph.

diabetes has adverse effects on AMPK activity in murine oocytes by skewing AMP/ATP ratios. We find that AMPK phosphorylation and its activity are affected by insulin resistance and that AMPK activation is important for the translocation of SLC2A8 to the plasma membrane of TS cells. Our data imply that AMPK is an important player in the trophectoderm of the preimplantation development that is vital for successful implantation, and that AMPK dysfunction may contribute to decreased 2-deoxyglucose uptake in both TS and blastocysts.

Furthermore, we show in our insulin-resistant model that down-regulation of IGF1R induces apoptosis, and that stimulation of AMPK with either AICAR or phenformin partially rescues the TS cells from apoptosis. In addition, inhibition of AMPK with compound C negates the anti-apoptotic effects of AICAR. These experiments in combination with previous studies 
support the findings that down-regulation of IGF1R leads to apoptosis. It has been shown that elevated IGF1 results in down-regulation of IGF1 R expression in the blastocyst leading to an increase in apoptosis and pregnancy resorption (Chi et al. 2000, Pinto et al. 2002 b). Recently, we have demonstrated that treatment of these insulinresistant blastocyst with AICAR or metformin results in improvements in glucose utilization and pregnancy outcomes (Eng et al. 2007). In this report, we extend these in vivo findings by showing that AMPK activation leads to activation of downstream components of the insulin signaling pathway to improve 2-deoxyglucose uptake and reverse apoptosis. Previously activated AMPK has been shown to rescue cardiomyocytes and rat hepatocytes from apoptosis under states of hypoxic injury and from destructive toxins respectively (Larsen et al. 2002, Terai et al. 2005). In addition, in colon cancer, AMPK activation induces an anti-proliferation mechanism under stimulation via AICAR with activated p53 (Su et al. 2007). The role of AMPK in cell proliferation and survival remains poorly documented and somewhat controversial. However, we are the first to report that activated AMPK protects TS cells from the apoptotic effects of insulin resistance characteristic of maternal hyperinsulinemia, suggesting that the treatment targeted at AMPK activation could increase pregnancy success.

Lastly, we have demonstrated crosstalk between IGF1R signaling and AMPK activation in the pathophysiology of maternal insulin resistance leading to blastocyst apoptosis. There are several points of convergence between IGF1R and AMPK: the observation that AMPK promotes the translocation of SLC2As from intracellular compartments to the cell surface and that activation of AMPK by AICAR strongly stimulates gene expression of IGF1R in $\beta$-islet cells, indicating AMPK regulation of IGF1R gene (Jakobsen et al. 2001, Raile et al. 2005). Other studies also have revealed that AMPK activation with metformin increases PI3K/PKB signaling pathways in other cell types. Although mechanisms underlying insulin resistance are not yet fully understood, alterations in the insulin-induced activation of the PI3K/AKT signaling pathway undoubtedly play a critical role in both apoptosis and glucose uptake in TS cells (Bertrand et al. 2006). Bertrand et al. has shown that AMPK activation with phenformin, metformin, and other AMPK activators counteracts insulin resistance in cardiomyocytes via the AKT/PKB pathway. Also, the PI3K/AKT pathway is required for embryo survival (Riley et al. 2005, 2006, Riley \& Moley 2006). These findings show that activation of AMPK reverses the negative effects on IGF1R signaling possibly through phosphorylation of downstream IGF1R signaling molecules, AKT/PKB or PI3K in the TS cell.

These experiments, taken together, demonstrate that activation of AMPK induces downstream events of IGF1R signaling such as the PI3K/AKT/mTOR pathway, increases insulin-stimulated 2-deoxyglucose uptake, and induces anti-apoptotic affects possibly by the activation of PI3K/AKT. The critical importance of PI3K pathway in preimplantation embryo survival and pregnancy outcome has been demonstrated previously (Riley et al. 2006). The findings of this study imply that down-regulation of IGF1R and the decrease in AMPK activation in the extra-embryonic cell are related events in hyperinsulinemia and insulin resistance. Possible etiologies include skewing of AMP/ATP ratio or possible AMPK regulation of the IGF1R gene. The studies also suggest that the decrease in 2-deoxyglucose transport and increase in apoptosis caused by hyperinsulinemia can be rescued by AMPK activation leading to cell survival and normalization of glucose utilization.

\section{Materials and Methods}

\section{Construction of SiRNA}

siRNA was generated using the Ambion Silencer siRNA Construction Kit (Austin, TX, USA), according to the manufacturer's protocol. Starting primer pairs (Integrated DNA Technologies; Coralville, IA, USA) were designed to target sequences from the cDNA sequences of mouse Igf1r (accession number AB006442). Control scramble siRNAs were purchased from Ambion. Sense and anti-sense primers corresponding to the following target was used: Igf1r-target (5'-TCTCAAGGATATTGGCCTTT-3'). Next, the target sequence was extended with the sequence $5^{\prime}$-CCTGTCTC- $3^{\prime}$ at the $3^{\prime}$ end.

\section{Cell culture and transfection}

TS cell lines were a generous gift from Dr Janet Rossant (Samuel Lunenfeld Research Institute, Mount Sinai Hospital, Toronto, Canada). The TS lines were maintained in the presence of mouse embryonic fibroblasts-conditioned media (MEF-CM). MEF-CM was generated as described previously (Rossant 2001). TS cells were cultured in $70 \%$ MEF-CM and 30\% TS medium supplemented with $25 \mathrm{ng} / \mathrm{ml}$ fibroblast growth factor 4 and $1 \mu \mathrm{g} / \mathrm{ml}$ heparin (Sigma). Prior to transfection, the cells were split and seeded for $24 \mathrm{~h}$, and then transfection was carried out using FuGENE 6 (Roche applied science). Transient transfection was confirmed by western immunoblot analysis $72 \mathrm{~h}$ post-transfection.

\section{AMP and ATP level measurements}

TS cells were washed with PBS, and protein extracted with $0.30 \mathrm{M}$ PCA for $5^{\prime}$-AMP assays or $0.10 \mathrm{~N} \mathrm{NaOH}$ for ATP assays. ATP was assayed as described by Chi (Chen et al. 2006). 5'-AMP was measured by stimulation of phosphorylase a as described previously in oocytes (Ratchford et al. 2007). Enzymes were obtained from Sigma Chemical Co., Roche, and Calbiochem (San Diego, CA, USA). Rabbit liver glycogen type III was from Sigma; other chemicals used were of reagent grade. 


\section{TUNEL assay}

Apoptosis was assayed following TS transfection and treatment with $250 \mu \mathrm{M}$ AICAR (Sigma) for $2 \mathrm{~h}$, using TUNEL. TS cells were fixed in $2 \%$ paraformaldehyde (Sigma) for $1 \mathrm{~h}$ and permeabilized in $0.1 \%$ Triton X-100 (Sigma) for $2 \mathrm{~min}$. Apoptosis was assessed using the In Situ Cell Death Detection Kit, TMR (Roche Diagnostics). After the TUNEL assay was performed, the nuclei of the TS cells were stained using $4 \mu \mathrm{M}$ To-Pro-3-iodide (Molecular Probes, Eugene, OR, USA) for 20 min. Images were taken using a Nikon C1 laser scanning confocal microscope.

\section{Flow cytometry}

TS cells transfected with $\operatorname{Igf1} r$ siRNA were seeded at $2.5 \times 10^{6}$ per $10 \mathrm{~cm}$ dish. The cells were cultured in the presence of $250 \mu \mathrm{M}$ AICAR for $2 \mathrm{~h}$. The TS cells were harvested, washed two times with PBS, and the TUNEL assay was performed. The cells were analyzed for TUNEL using a BD FACSCalibur flow cytometer (BD Biosciences, Rockville, MD, USA). A gate was drawn and the percentage of cells within the gate was determined using CellQuest software (BD Biosciences).

\section{$\left[{ }^{3} \mathrm{H}\right] 2-$ Deoxyglucose uptake}

2-Deoxyglucose uptake in TS cells transfected with Igf1r siRNA and treated with $250 \mu \mathrm{M}$ AICAR (Sigma) with $\pm 1 \mu \mathrm{M}$ insulin (bovine pancreas) (Sigma) was measured using a radioactive analytic procedure. TS cells $72 \mathrm{~h}$ post-transfection were treated for $2 \mathrm{~h}$ in culture in the presence $250 \mu \mathrm{M} \mathrm{AICAR}$ and $30 \mathrm{~min}$ of $1 \mu \mathrm{M}$ insulin and incubated at $37^{\circ} \mathrm{C}$ in serum-free RPMI. At the end of incubation, the cells were washed with KRP buffer $\left(128 \mathrm{mM} \mathrm{NaCl}, 4.7 \mathrm{mM} \mathrm{KCl}, 1.25 \mathrm{mM} \mathrm{MgSO}_{4}, 5 \mathrm{mM}\right.$ $\mathrm{Na}_{2} \mathrm{HPO}_{4}$, and $1.25 \mathrm{CaCl}_{2},(\mathrm{pH}$ 7.4) with $\mathrm{HCl})$. The cells were further incubated with $\left[{ }^{3} \mathrm{H}\right] 2-\mathrm{DG}\left(1 \mathrm{mCi} / \mathrm{ml}\left[{ }^{3} \mathrm{H}\right] 2-\mathrm{DG}\right.$ and $200 \mathrm{mM}$ cold DG) (Sigma) for $6 \mathrm{~min}$. The uptake was terminated by the addition of ice-cold KRP. Cell-associated radioactivity was determined from the lysed cells using $1 \mathrm{ml}$ of $1 \%$ Triton in PBS and the aliquots were neutralized to be estimated in a scintillation counter. As a negative control $20 \mu \mathrm{mol} / \mathrm{l}$ cytochalasin B (Sigma) was assessed to block 2-deoxyglucose transport.

\section{Western immunoblot}

TS cells were cultured in DMSO, $250 \mu \mathrm{M}$ AICAR, $10 \mathrm{mM}$ phenformin, or $250 \mu \mathrm{M}$ AICAR with $125 \mu \mathrm{M}$ compound $\mathrm{C}$ for $2 \mathrm{~h}$ and subsequently subjected to western immunoblot analysis. Twenty micrograms of protein were loaded and subjected to western blot analysis or $100 \mu \mathrm{g}$ of cell lysate were immunoprecipitated with the indicated antibody for $1 \mathrm{~h}$. Samples were subjected to SDS-PAGE and transferred to nitrocellulose. Blots were blocked for $1 \mathrm{~h}$ at RT in $5 \%$ milk in TBS-T. The blots were probed overnight at $4{ }^{\circ} \mathrm{C}$ in $1 \%$ milk in TBS-T with the indicated antibodies: IGF1R $\beta$ and PI3K (Santa Cruz Biotechnology, Santa Cruz, CA, USA); IRS1, p-mTOR,
p7056K, pS6Kribo, AMPK, pAMPK (Cell Signaling, Danvers, MA, USA); and AKT (Covance, Princeton, NJ, USA), p-ACC (Upstate, Charlottesville, VA, USA). The HRP-conjugated secondary antibody (either goat anti-rabbit or goat antimouse; Sigma) was used for detection and visualized using SuperSignal West Dura.

\section{Cell surface photolabeling of SLC2A8}

TS cells were cultured in the presence of $250 \mu \mathrm{M}$ AICAR for $2 \mathrm{~h}$ and stimulated with $1 \mu \mathrm{M}$ insulin for $30 \mathrm{~min}$ and analyzed for cell surface SLC2As, as described previously (Calderhead et al. 1990). The cells were photolabeled with $250 \mu \mathrm{Ci}$ biotin membrane-impermeant reagent Bio-ATB-BMPA (Toronto Research Chemicals Inc., North York, Ontario, Canada) ( $3 \mathrm{~min}$ ) in $3.0 \mathrm{ml}$ albumin-free buffer after washing with a $1 \%$ albumin and Krebs-Ringer buffer. The samples were immediately irradiated for $3 \mathrm{~min}$ in a RPR-100 photochemical reactor (RPR-3000 lamps). Following irradiation, the cells were washed with $1 \%$ albumin PBS buffer at $18^{\circ} \mathrm{C}$. The cells were washed three times with Thesit (Anatrace, Maumee, $\mathrm{OH}$, USA) buffer and resuspended and washed with homogenization buffer containing $10 \mathrm{mM}$ Tris- $\mathrm{HCl}, 0.5 \mathrm{mM}$ EDTA, and $255 \mathrm{mM}$ sucrose $(\mathrm{pH} 7.2)$ at $18{ }^{\circ} \mathrm{C}$. The plasma membrane extracts were isolated using centrifugation then solubilized in solubilization buffer ( $2 \%$ Thesit) for immunoprecipitation for electrophoresis with streptavidin-agarose beads (Sigma), a substrate of biotin and blotted with anti-GLUT8 (Carayannopoulos et al. 2000).

\section{Phosphatidylinositol 3-kinase activity}

In vitro phosphorylation of phosphatidylinositol was measured, as described previously (Backer et al. 1992). Subconfluent TS cells grown in $10 \mathrm{~cm}$ dishes overnight and transfected, as described previously, with $\lg f 1 r$ siRNA followed by $250 \mu \mathrm{M}$ AICAR for $2 \mathrm{~h}$ and processed as described previously (Backer et al. 1992). The cells were then washed with ice-cold PBS TLC plates were developed in $\mathrm{CHC}_{3}: \mathrm{CH}_{3} \mathrm{OH}: \mathrm{H}_{2} \mathrm{O}: \mathrm{NH}_{4} \mathrm{OH}$, dried, and visualized by autoradiography. The radioactivity in spots that co-migrated with Ptdlns-4P was measured by densitometry.

\section{Statistical analysis}

All experiments were completed at least three times. Results are expressed as mean \pm s.D. of three separate experiments. The glucose transport, TUNEL, and PI3K assays were analyzed statistically by ANOVA with Fisher's post hoc test; significance was defined as $P<0.05$.

\section{Declaration of interest}

The authors declare that there is no conflict of interest that could be perceived as prejudicing the impartiality of the research reported. 


\section{Funding}

This work was supported by the National Institutes of Health RO1 DK070351 (K H M) and T32 HDO49305-03 (E L).

\section{References}

Adamiak SJ, Mackie K, Watt RG, Webb R \& Sinclair KD 2005 Impact of nutrition on oocyte quality: cumulative effects of body composition and diet leading to hyperinsulinemia in cattle. Biology of Reproduction $\mathbf{7 3}$ 918-926.

Backer JM, Schroeder GG, Kahn CR, Myers MG, Wilden PA, Cahill DA \& White MF 1992 Insulin stimulation of phosphatidylinositol 3-kinase activity maps to insulin receptor regions required for endogenous substrate phosphorylation. Journal of Biological Chemistry 267 1367-1374.

Bakhle YS \& Chelliah R 1983 Effect of streptozotocin-induced diabetes on the metabolism of ADP, AMP and adenosine in the pulmonary circulation of rat isolated lung. Diabetologia 24 455-459.

Barnes BR, Marklund S, Steiler TL, Walter M, Hjalm G, Amarger V, Mahlapuu M, Leng Y, Johansson C, Galuska D et al. 2004 The 5'-AMPactivated protein kinase gamma3 isoform has a key role in carbohydrate and lipid metabolism in glycolytic skeletal muscle. Journal of Biological Chemistry 279 38441-38447.

Bertrand L, Ginion A, Beauloye C, Hebert AD, Guigas B, Hue L \& Vanoverschelde JL 2006 AMPK activation restores the stimulation of glucose uptake in an in vitro model of insulin-resistant cardiomyocytes via the activation of protein kinase B. American Journal of Physiology. Heart and Circulatory Physiology $291 \mathrm{H} 239-\mathrm{H} 250$.

Calderhead DM, Kitagawa K, Tanner LI, Holman GD \& Lienhard GE 1990 Insulin regulation of the two glucose transporters in 3T3-L1 adipocytes. Journal of Biological Chemistry 265 13801-13808.

Carayannopoulos MO, Chi MM, Cui Y, Pingsterhaus JM, McKnight RA, Mueckler M, Devaskar SU \& Moley KH 2000 GLUT8 is a glucose transporter responsible for insulin-stimulated glucose uptake in the blastocyst. PNAS 97 7313-7318.

Chan ES, Fernandez P \& Cronstein BN 2007 Adenosine in inflammatory joint diseases. Purinergic Signalling 3 145-152.

Chen J, Hudson E, Chi MM, Chang AS, Moley KH, Hardie DG \& Downs SM 2006 AMPK regulation of mouse oocyte meiotic resumption in vitro. Developmental Biology 291 227-238.

Chi MM-Y, Schlein AL \& Moley KH 2000 High insulin like growth factor I (IGF-1) and insulin concentrations trigger apoptosis in the mouse blastocyst via down-regulation of the IGF-1 receptor. Endocrinology 141 4784-4792.

Culmsee C, Monnig J, Kemp BE \& Mattson MP 2001 AMP-activated protein kinase is highly expressed in neurons in the developing rat brain and promotes neuronal survival following glucose deprivation. Journal of Molecular Neuroscience 17 45-58.

Dagher Z, Ruderman N, Tornheim K \& Ido Y 1999 The effect of AMPactivated protein kinase and its activator AICAR on the metabolism of human umbilical vein endothelial cells. Biochemical and Biophysical Research Communications 265 112-115.

Diaz E, Cardenas M, Ariza AC, Larrea F \& Halhali A 2005 Placental insulin and insulin-like growth factor I receptors in normal and preeclamptic pregnancies. Clinical Biochemistry 38 243-247.

Downs SM, Hudson ER \& Hardie DG 2002 A potential role for AMPactivated protein kinase in meiotic induction in mouse oocytes. Developmental Biology 245 200-212.

Eng GS, Sheridan RA, Wyman A, Chi MM, Bibee KP, Jungheim ES \& Moley KH 2007 AMP kinase activation increases glucose uptake, decreases apoptosis, and improves pregnancy outcome in embryos exposed to high IGF-I concentrations. Diabetes 56 2228-2234.

Gilbert C, Valois M \& Koren G 2006 Pregnancy outcome after first-trimester exposure to metformin: a meta-analysis. Fertility and Sterility $\mathbf{8 6}$ 658-663.

Gruber HE, Hoffer ME, McAllister DR, Laikind PK, Lane TA, SchmidSchoenbein GW \& Engler RL 1989 Increased adenosine concentration in blood from ischemic myocardium by AICA riboside. Effects on flow, granulocytes, and injury. Circulation 80 1400-1411.
Guigas B, Bertrand L, Taleux N, Foretz M, Wiernsperger N, Vertommen D, Andreelli F, Viollet B \& Hue L 2006 5-Aminoimidazole-4-carboxamide1-beta-D-ribofuranoside and metformin inhibit hepatic glucose phosphorylation by an AMP-activated protein kinase-independent effect on glucokinase translocation. Diabetes 55 865-874.

Hardie DG, Scott JW, Pan DA \& Hudson ER 2003 Management of cellular energy by the AMP-activated protein kinase system. FEBS Letters $\mathbf{5 4 6}$ 113-120.

Hiromura K, Monkawa T, Petermann AT, Durvasula RV \& Shankland SJ 2002 Insulin is a potent survival factor in mesangial cells: role of the PI3kinase/Akt pathway. Kidney International 61 1312-1321.

Homburg R 2006 Pregnancy complications in PCOS. Best Practice and Research. Clinical Endocrinology and Metabolism 20 281-292.

Ido Y, Carling D \& Ruderman N 2002 Hyperglycemia-induced apoptosis in human umbilical vein endothelial cells: inhibition by the AMP-activated protein kinase activation. Diabetes 51 159-167.

Jakobsen SN, Hardie DG, Morrice N \& Tornqvist HE 2002 5'-AMPactivated protein kinase phosphorylates IRS- 1 on Ser-789 in mouse C2C12 myotubes in response to 5-aminoimidazole-4-carboxamide riboside. Journal of Biological Chemistry 276 46912-46916.

Ju JS, Gitcho MA, Casmaer CA, Patil PB, Han DG, Spencer SA \& Fisher JS 2007 Potentiation of insulin-stimulated glucose transport by the AMPactivated protein kinase. American Journal of Physiology. Cell Physiology 292 C564-C572.

Kahn BB, Carling D \& Hardie DG 2005 AMP-activated protein kinase: ancient energy gauge provides clues to modern understanding of metabolism. Cell Metabolism 1 15-25.

Kim SJ, Winter K, Nian C, Tsuneoka M, Koda Y \& McIntosh CH 2005 Glucose-dependent insulinotropic polypeptide (GIP) stimulation of pancreatic beta-cell survival is dependent upon phosphatidylinositol 3-kinase $(\mathrm{PI} 3 \mathrm{~K}) /$ protein kinase B ( $\mathrm{PKB}$ ) signaling, inactivation of the forkhead transcription factor Foxo1, and down-regulation of bax expression. Journal of Biological Chemistry $28022297-22307$.

Kim YI, Lee FN, Choi WS, Lee S \& Youn JH 2006 Insulin regulation of skeletal muscle PDK4 mRNA expression is impaired in acute insulinresistant states. Diabetes 55 2311-2317.

Lang T, Yu L, Tu Q, Jiang J, Chen Z, Xin Y, Liu G \& Zhao S 2000 Molecular cloning, genomic organization, and mapping of PRKAG2, a heart abundant gamma2 subunit of 5'-AMP-activated protein kinase, to human chromosome 7q36. Genomics 70 258-263.

Larsen AK, Moller MT, Blankson H, Samari HR, Holden L \& Seglen PO 2002 Naringin-sensitive phosphorylation of plectin, a cytoskeletal crosslinking protein, in isolated rat hepatocytes. Journal of Biological Chemistry 277 34826-34835.

McGraw S, Robert C, Massicotte L \& Sirard MA 2003 Quantification of histone acetyltransferase and histone deacetylase transcripts during early bovine embryo development. Biology of Reproduction 68 383-389.

Morales AV, Serna J, Alarcon C, De la Rosa EJ \& De Pablo F 1997 Role of prepancreatic (pro)insulin and the insulin receptor in prevention of embryonic apoptosis. Endocrinology 138 3967-3975.

Morgensztern D \& McLeod HL 2005 PI3K/Akt/mTOR pathway as a target for cancer therapy. Anticancer Drugs 16 797-803.

Nichols J, Zevnik B, Anastassiadis K, Niwa H, Klewe-Nebenius D, Chambers I, Scholer H \& Smith A 1998 Formation of pluripotent stem cells in the mammalian embryo depends on the POU transcription factor Oct4. Cell 95 379-391.

Pinto AB, Carayannopoulos MO, Hoehn A, Dowd L \& Moley KH 2002a Glucose transporter 8 expression and translocation are critical for murine blastocyst survival. Biology of Reproduction 66 1729-1733.

Pinto AB, Schlein AL \& Moley KH $2002 b$ Preimplantation exposure to high insulin-like growth factor I concentrations results in increased resorption rates in vivo. Human Reproduction 17 457-462.

Raile K, Klammt J, Laue S, Garten A, Bluher M, Kralisch S, Kloting N \& Kiess W 2005 Glucose concentration and AMP-dependent kinase activation regulate expression of insulin receptor family members in rat islets and INS-1E beta cells. Diabetologia $\mathbf{4 8} 1798-1809$.

Ralston A \& Rossant J 2006 How signaling promotes stem cell survival: trophoblast stem cells and Shp2. Developmental Cell 10 275-276.

Ratchford AM, Chang AS, Chi MM, Sheridan R \& Moley KH 2007 Maternal diabetes adversely affects AMP-activated protein kinase activity and cellular metabolism in murine oocytes. American Journal of Physiology. Endocrinology and Metabolism 293 E1198-E1206. 
Riedemann J \& Macaulay VM 2006 IGF1R signalling and its inhibition. Endocrine-Related Cancer 13 S33-S43.

Riley JK \& Moley KH 2006 Glucose utilization and the PI3-K pathway: mechanisms for cell survival in preimplantation embryos. Reproduction 131 823-835.

Riley JK, Carayannopoulos MO, Wyman AH, Chi M, Ratajczak CK \& Moley KH 2005 The PI3K/Akt pathway is present and functional in the preimplantation mouse embryo. Developmental Biology 284 377-386.

Riley JK, Carayannopoulos MO, Wyman AH, Chi M \& Moley KH 2006 Phosphatidylinositol 3-kinase activity is critical for glucose metabolism and embryo survival in murine blastocysts. Journal of Biological Chemistry 281 6010-6019.

Rossant J 2001 Stem cells from the Mammalian blastocyst. Stem Cells 19 $477-482$.

Rossant J 2008 Stem cells and early lineage development. Cell 132 527-531.

Satoh H, Nguyen MT, Miles PD, Imamura T, Usui I \& Olefsky JM 2004 Adenovirus-mediated chronic 'hyper-resistinemia' leads to in vivo insulin resistance in normal rats. Journal of Clinical Investigation 114 224-231.

Su RY, Chao Y, Chen TY, Huang DY \& Lin WW 2007 5-Aminoimidazole-4carboxamide riboside sensitizes TRAIL- and TNF $\alpha$-induced cytotoxicity in colon cancer cells through AMP-activated protein kinase signaling. Molecular Cancer Therapeutics 6 1562-1571.

Tanaka S 2006 Derivation and culture of mouse trophoblast stem cells in vitro. Methods in Molecular Biology 329 35-44.

Tanaka S, Kunath T, Hadjantonakis AK, Nagy A \& Rossant J 1998 Promotion of trophoblast stem cell proliferation by FGF4. Science 282 2072-2075.

Terai K, Hiramoto Y, Masaki M, Sugiyama S, Kuroda T, Hori M, Kawase I \& Hirota H 2005 AMP-activated protein kinase protects cardiomyocytes against hypoxic injury through attenuation of endoplasmic reticulum stress. Molecular and Cellular Biology 25 9554-9575.
Thierry van Dessel HJ, Lee PD, Faessen G, Fauser BC \& Giudice LC 1999 Elevated serum levels of free insulin-like growth factor I in polycystic ovary syndrome. Journal of Clinical Endocrinology and Metabolism 84 3030-3035.

Woollhead AM, Scott JW, Hardie DG \& Baines DL 2005 Phenformin and 5-aminoimidazole-4-carboxamide-1-beta-D-ribofuranoside (AICAR) activation of AMP-activated protein kinase inhibits transepithelial $\mathrm{Na}+$ transport across H441 lung cells. Journal of Physiology 566 781-792.

Yakar S, Kim H, Zhao H, Toyoshima Y, Pennisi P, Gavrilova O \& Leroith D 2005 The growth hormone-insulin like growth factor axis revisited: lessons from IGF-1 and IGF-1 receptor gene targeting. Pediatric Nephrology 20 251-254.

Ye JM, Dzamko N, Hoy AJ, Iglesias MA, Kemp B \& Kraegen E 2006 Rosiglitazone treatment enhances acute AMP-activated protein kinasemediated muscle and adipose tissue glucose uptake in high-fat-fed rats. Diabetes 55 2797-2804.

Zang M, Zuccollo A, Hou X, Nagata D, Walsh K, Herscovitz H, Brecher P, Ruderman NB \& Cohen RA 2004 AMP-activated protein kinase is required for the lipid-lowering effect of metformin in insulinresistant human HepG2 cells. Journal of Biological Chemistry 279 47898-47905.

Zernicka-Goetz M 2002 Patterning of the embryo: the first spatial decisions in the life of a mouse. Development 129 815-829.

Received 13 April 2008

First decision 7 May 2008

Accepted 23 June 2008 